\title{
Clusters in Social Behaviour of Female Domestic Cats (Felis silvestris catus) Living in Confinement
}

\author{
Ruud van den Bos* and Han de VRIES** \\ *Department of Ethics, History and Alternatives of Animal Experiments, \\ Medical Faculty, University of Leiden; Anthrozoology Institute, \\ Department of Biology, University of Southampton, Southampton U.K. \\ **Ethology and Socio-ecology, Department of Comparative Physiology, \\ University of Utrecht, Utrecht, the Netherlands
}

\begin{abstract}
Associations between different agonistic and affiliative behavioural patterns of female domestic cats (Felis silvestris catus) were studied. In three groups of intact cats living in confinement frequencies of fourteen agonistic and affiliative behavioural patterns were recorded. The technique of factor analysis (Principal Components Analysis followed by varimax rotation on a dyads $\mathrm{X}$ behavioural patterns matrix) was used to detect clusters in these behavioural patterns. Five factors (or types of interindividual relationships) were extracted per group. They accounted collectively for at least $77 \%$ of the total variance present in the data. Although differences existed between groups with respect to behavioural patterns included in each factor, four clusters of behaviours could be discriminated: (I) social rubbing, lordosis and rolling in front of partner (sexual behaviour), (II) allogrooming, social sniffing, nosing, sniffing rear and treading (inspection-affiliative behaviour), (III) offensive behaviour and staring, and (IV) defensive behaviour and staring. The role of these clusters in group living is discussed.
\end{abstract}

\section{Introduction}

Free-ranging domestic cats (Felis silvestris catus) live either solitary or in groups depending on the distribution and abundance of food (for reviews: Bradshaw 1992; Bradshaw \& Brown 1992; Liberg \& Sandell 1988). Females with their dependent offspring form the core of groups, whereas males are only loosely attached to such groups and wander between them (review: Liberg \& Sandell 1988). The last decade has shown a growing interest in various aspects of social behaviour of free-ranging cats (e.g. Brown 1993; Dards 1983; Liberg 1980; Macdonald et al. 1987; Natoli 1985; Natoli \& De Vito 1991), partly because the domestic cat has been considered to be a good model animal to study the factors and processes leading to group-living in the family of felids (e.g. Macdonald et al. 1987). At the same time there has been a growing interest in social behaviour of cats under confined conditions (e.g. van den Bos \& de Cock Buning 1994a,b; van den Bos 1995a,b,c,d; Brown 1993; Feldman 1994; Podberscek et al. 1991; Smith et al. 1994), partly because of questions concerning the welfare of cats in groups under these conditions and partly because studies under confined conditions contribute to understanding cat social behaviour under free-ranging conditions (see van den Bos \& de Cock Buning 1994a).

Leyhausen (1979) was among the first to publish a comprehensive and insightful study on social behaviour of domestic cats (in confinement). Despite continuous research efforts since (see above) the picture of the cat's social 
behaviour is far from being complete. This is mainly due to the variation between studies in such factors as subjects (males and females), sexual status of subjects (intact and neutered), breeding status (breeding and nonbreeding) and living conditions (free-ranging and confined); a problem generally inherent to studying the behaviour of domesticated animals. Still, these studies have already revealed insight into such varying topics as dominance hierarchies and the existence of dominance and submissive behaviours (e.g. van den Bos \& de Cock Buning 1994a,b; van den Bos 1995 a,b,d; Feldman 1994; Natoli, \& De Vito 1991; Macdonald et al. 1987; Podberscek et al. 1991), the role of allogrooming (van den Bos 1995c) and cooperation between females in raising their offspring (Macdonald et al. 1987). Yet, an important aspect still unknown is how and which behavioural patterns collectively play a role in maintaining group cohesion or in regulating relationships between females in groups either under free-ranging or confined conditions. Such knowledge is crucial for insight into how in socially opportunistic species like domestic cats (or felids in general), behavioural patterns come to play a specific role between members of groups, for instance the relationship between the role of these patterns and their origin (maternal, sexual or predatory behaviour; cf. Omark 1980), how flexible the use of such patterns is and whether different patterns may have similar meanings. As part of an ongoing long-term study of social behaviour of cats (van den Bos \& de Cock Buning 1994a,b; van den Bos 1995a,b,c,d) the present study therefore concentrated on the question of which social behavioural patterns of female domestic cats are associated or clustered. For this purpose the pattern of similarities and dissimilarities between social behavioural patterns was analysed in three groups of female domestic cats in confinement using the technique of factor analysis (cf. Colmenares 1983).

\section{Materials and Methods}

\section{Subjects and housing conditions}

Three groups of intact females (hereafter re- ferred to as groups A, B and C) living in confinement were used. Details of one group group A - have been published elsewhere (van den Bos \& de Cock Buning 1994a). In brief, group A consisted of 10 intact adult females (age range 2-5 yr), which had been together for a period of 3 months when observations started. Originally, groups $\mathrm{B}$ and $\mathrm{C}$ were one group. The members of this group had been together for a period of at least 6 months, when it was split into two groups (3-4 months before observations started). Group B consisted of 8 intact adult females (age: $1-2$ yr) and 2 juveniles (age: $0.6 \mathrm{yr}$ ). The latter were no descendants of the females in this group. Group C consisted of 7 intact adult females (age: $0.8-2$ yr) and 2 juveniles (age: $0.3 \mathrm{yr}$ ). The latter were no descendants of the females in this group. Neither in group A nor in groups B and $C$ coefficients of relatedness could be calculated since information on parenthood was lacking (cf. van den Bos \& de Cock Buning 1994a).

All groups were housed under standard laboratory conditions (see van den Bos \& de Cock Buning 1994a for details). In brief, each colony room consisted of (i) a floor area on which food bowls, a water fountain and litter trays were present, (ii) poles with shelfs, on which animals could lie, sit etc., and (iii) a boxcontaining complex, in which animals could lie, sit etc. The cats were kept on a 12-12 h daynight cycle (lights on: 07:30-19:30 h). Temperature in the rooms was maintained at 21 degrees Celsius. Rooms were cleaned once daily, either in the morning or in the afternoon depending on the specific group. Cats were fed standard laboratory dryfood (Dokat (R)) once daily in the afternoon. Water was available throughout the day. Population densities for the groups (A, B and C) were $0.42,0.46$ and 0.60 cat per square meter respectively. All females were intact and showed regular oestrus cycles (see van den Bos \& de Cock Buning 1994a). Females had no sexual contact with males when in oestrus and hence no kittens were born in these groups.

\section{Observational regimen and behaviours}

Group A was observed for a period of $13 \mathrm{wk}$, 
group B for a period of 9 wk and group C for a period of $12 \mathrm{wk}$. Details of the observational regimen have been given elsewhere (van den Bos \& de Cock Buning 1994a). In brief, in all cases the first two weeks served to familiarize the cats with the presence of an observer in the colony room. Behavioural observations were made during morning $(09.30-12.30 \mathrm{~h})$ and/or afternoon $(13.00-16.30 \mathrm{~h})$ sessions on all but weekend days of the week. For all groups data were obtained on the occurrence (frequencies) of different affiliative and agonistic behavioural patterns between cats (Ethogram: Table 1) using continuous recording sampling (Martin \& Bateson 1986). It should be noted that for group $\mathrm{A}$ the patterns treading and biting were not included in the ethogram (van den Bos \& de Cock Buning 1994a). Only behavioural patterns which were unambiguously directed to other cats were included in the actor-receiver matrices. The observer chose its position in such a way that all cats could be observed at the same time (cf. van den Bos \& de Cock Buning 1994a).

At each 15th min the locations of the cats in the colony rooms were denoted on predrawn maps of the colony rooms as well as which cats were within $0.5 \mathrm{~m}$ of one another (proximity; van den Bos \& de Cock Buning 1994a). Affiliative behaviours were recorded between these spatial recordings; agonistic behaviours were recorded throughout. The locations of individual cats in the colony room and the proximity scores for the different pairs of cats are not reported in this paper (see van den Bos \& de Cock Buning 1994a for group A). In total, $72 \mathrm{~h}$ $28 \mathrm{~min}$ were sampled for affiliative behaviour and $89 \mathrm{~h} 23 \mathrm{~min}$ for agonistic behaviour for group A. For groups B and C these totalled: B: $46 \mathrm{~h} 30 \mathrm{~min}$ and $52 \mathrm{~h} 45 \mathrm{~min}$; C: $48 \mathrm{~h} 44 \mathrm{~min}$ and $54 \mathrm{~h} 00 \mathrm{~min}$.

Table 1. Ethogram of cat social behaviour (van den Bos \& de Cock Buning 1994a).

BEHAVIOUR
allogrooming
social rubbing
social sniffing
sniffing rear
touch noses
lordosis
rolling in front of partner
mounting
social play
treading
bite

Offensive behaviour

Defensive behaviour

Staring

\section{DESCRIPTION \\ Affiliative Behaviour}

licking the head, body, tail etc. of another cat;

moving the head or flank along the head or flank of another cat in a sinuous movement;

sniffing the body of another cat, excluding the anogenital region and the nasal region;

sniffing the anogenital region of another cat;

(aiming to) sniff at another cat's nasal region;

exposing the anogenital region by elevating hindquarters, accompanied by treading movements of the hindlegs and sideways positioning of the tail;

lying on the dorsum and rolling in front of another cat;

mounting another cat with treading movements of the hindlegs along the flanks of the recipient cat, while holding the recipient firmly at the nape of the neck;

combination of friendly chasing, biting and wrestling; postures are assumed which do not indicate any agonistic interactions;

rhythmically moving forepaws with extension and retraction of claws on body of another cat;

biting another cat without any overt aggression and outside context of play;

\section{Agonistic Behaviour}

combination of the following behavioural elements:

(slowly) approaching another cat (lowered head); running in pursuit of another cat, erect ears swiveled to point back on the head; hairs on back and tail erected; lashing tail; panting, salivating; cuffing, growling, yowling; narrowing of the pupils;

combination of the following behavioural elements:

lowering of hindquarters; pilo-erection; flattening of the ears to the head such that they tend to flush with the top of the head; hissing, spiting; growling; rolling on the dorsum to expose claws; cuffing; dilation of the pupils;

fixing the gaze at another cat; 


\section{Data analysis}

In order to carry out factor analysis the following matrix was prepared for each group: rows: dyads; columns: behavioural patterns. Each cell of this matrix contained the frequency with which the one individual of a dyad (row) performed a behavioural pattern (column) towards the other individual of the dyad. In groups B and C only the adults were included in the analysis. Columns which contained more than $90 \%$ of zero entries were discarded from the analysis (exclusion criterion). Entries were $\log$-transformed $(\log [x+1])$ before factor analysis was carried out to stabilize the variance of the different columns (Slob, 1986, Ch.2).

Factor analysis was carried out in two steps (Harman 1967; see also Ferguson 1981).

In the first step a direct solution was obtained using Principal Components Analysis (PCA). This yielded a factor matrix containing factor loadings for each behavioural pattern (rows) per factor (columns). Only factors with eigenvalues (the contributions of factors to the total communality (the sum of the squares of the factor loadings of all factors)) larger than one were retained. One extra factor was retained if behavioural patterns were found to have low communalities, i.e., if the sums of squares of factor loadings across the different factors for those particular behavioural patterns were low. For, this indicates that the variation in those particular behavioural patterns was not sufficiently represented by the retained factors. It turned out that in all groups five factors were necessary, and sufficient, to explain at least $77 \%$ of the total variance (total communality) present in the data. Communalities of all behavioural patterns in the data sets were at least 0.65 .

Since a direct solution is in general not amenable to interpretation a rotation was carried out on the factor matrix during the second step, i.e., a derived solution was obtained (Harman 1967). Hereto a varimax rotation (Kaiser 1958) was used. Only the outcome of this procedure, i.e., the final factor matrix, is presented in the Results section. Each factor represents a type of interindividual relationship (see Colmenares 1983). Factor loadings larger than 0.40 or smaller than -0.40 in the final factor matrix are generally accepted as indicating strong contributions to a particular factor (see Ferguson 1981).

The whole factor analysis procedure was carried out using the SAS statistical package (SAS Institute Inc., USA).

\section{Results}

Following the exclusion criterion the behavioural patterns mount and social play in groups $\mathrm{A}, \mathrm{B}$ and $\mathrm{C}$, rolling in front of partner in groups $B$ and $C$, and staring in group $C$ were not included in the analyses.

Table 2 shows the final factor loading matrices. Social rubbing and lordosis turned out to be present in the same factor in all three groups. In the only group in which rolling in front of partner could be included in the analysis, this behavioural pattern was found to be associated with these two behavioural patterns. In group B biting was associated with social rubbing and lordosis.

Allogrooming and social sniffing were present in one factor in all three groups. Treading was associated with these behavioural patterns in groups $\mathrm{B}$ and $\mathrm{C}$. Nosing was found to be present in this factor in groups $\mathrm{B}$ and $\mathrm{C}$, whereas it constituted a separate factor with sniffing rear in group A. Sniffing rear emerged in a factor with allogrooming and social sniffing in group A, whereas it constituted a separate factor with social sniffing in group B. Allogrooming finally was found to be present with biting in a separate factor in group $\mathrm{C}$.

Defensive behaviour and offensive behaviour were found in separate factors in all three groups. Staring was present in both factors in group A and group B. Sniffing rear was associated with offensive behaviour in group $C$. Treading was associated with defensive behaviour in group $\mathrm{C}$.

\section{Discussion}

The following behavioural patterns were found to be consistently present in similar factors in the three different groups, in which they could be analysed: (i) social rubbing and lordosis, (ii) allogrooming and social sniffing, (iii) offensive behaviour and (iv) defensive be- 
Table 2. Final factor matrices for the different groups (A, B, C). Shown are factors with factor loadings $(\times 100)$; only values lager than $0.40(\times 100)$ are shown (see text). The labels indicate the different factors per group. Factors are not shown in decreasing order of variance explained per factor (per cent contribution to total communality) but such that different groups can easily compared with one another. In group A the five factors accounted for $83 \%$, in group $\mathrm{B}$ for $77 \%$ and in group $\mathrm{C}$ for $77 \%$ of the total variance present in the data.

\begin{tabular}{|c|c|c|c|c|c|c|c|c|c|c|c|c|c|c|c|}
\hline \% var. & $\begin{array}{c}F^{\mathrm{a}} 1 \\
24\end{array}$ & $\begin{array}{c}\mathrm{F}^{\mathrm{a}} 2 \\
19\end{array}$ & $\begin{array}{c}\mathrm{A} \\
\mathrm{F}^{\mathrm{a}} 4 \\
13\end{array}$ & $\begin{array}{c}\mathrm{F}^{\mathrm{a}} 3 \\
15\end{array}$ & $\begin{array}{c}\mathrm{F}^{\mathrm{a}} 5 \\
12\end{array}$ & $\begin{array}{c}\mathrm{F}^{\mathrm{b}} 2 \\
16\end{array}$ & $\begin{array}{c}\mathrm{F}^{\mathrm{b}} 1 \\
23\end{array}$ & $\begin{array}{c}\mathrm{B} \\
\mathrm{F}^{\mathrm{b}} 5 \\
11\end{array}$ & $\begin{array}{c}F^{b_{4}} \\
11\end{array}$ & $\begin{array}{c}F^{b} 3 \\
16\end{array}$ & $\begin{array}{c}F^{c} 2 \\
17\end{array}$ & $\begin{array}{c}\mathrm{F}^{c} 1 \\
19\end{array}$ & $\begin{array}{c}\mathrm{C} \\
\mathrm{F}^{\mathrm{c}} 3 \\
14\end{array}$ & $\begin{array}{c}\mathrm{F}^{\mathrm{5}} 5 \\
13\end{array}$ & $\begin{array}{r}\mathrm{F}^{\mathrm{c}} 4 \\
14\end{array}$ \\
\hline rolling & 91 & & & & & $X X$ & $X X$ & $x x$ & $x x$ & $x x$ & $X X$ & $x x$ & $x x$ & $x x$ & $x x$ \\
\hline lordosis & 84 & & & & & 87 & & & & & 90 & & & & \\
\hline rubbing & 83 & & & & & 62 & & & & & 83 & & & & \\
\hline biting & - & - & - & - & - & 75 & & & & & & & 95 & & \\
\hline grooming & & 74 & & & & & 83 & & & & & 46 & 69 & & \\
\hline sniffing & & 86 & & & & & 62 & 42 & & & & 83 & & & \\
\hline nosing & & & 93 & & & & 82 & & & & & 78 & & & \\
\hline sniff rear & & 66 & 46 & & & & & 90 & & & & & & & 64 \\
\hline treading & - & - & - & - & - & & 78 & & & & & 53 & & 56 & \\
\hline defensive & & & & 91 & & & & & 97 & & & & & 88 & \\
\hline staring & & & & 76 & 48 & & & & 44 & 76 & $x X$ & $x X$ & $x x$ & $X X$ & $x x$ \\
\hline offensive & & & & & 92 & & & & & 92 & & & & & 75 \\
\hline
\end{tabular}

$\%$ var. : per cent of variance explained by factor;

$X X \quad:$ too few data to include behaviour in analysis;

-- : behaviour not included in the ethogram of this group;

haviour. In addition, staring was found to be consistently associated with offensive and defensive behaviour in those groups in which the behavioural pattern was included in the analysis. Similarly, treading was found to be consistently associated with allogrooming and social sniffing in those groups in which this behavioural pattern could be analysed. This consistency across three different groups of females shows that these factors are representative for the female cat's social behaviour, at least in confinement.

The fact that some behavioural patterns appeared to be more variable as to which factors they belonged to, i.e., biting, sniffing rear and nosing, shows that differences between groups exist as well. It is beyond the scope and limit of this paper to elaborate on possible factors underlying these differences however.

With respect to sniffing rear and nosing, it seems reasonable to associate these behavioural patterns with allogrooming and social sniffing. For, sniffing rear is found with social sniffing (group B), whereas nosing is found with social sniffing and allogrooming (groups B and C) and with sniffing rear (group A). Furthermore, despite the fact that rolling in front of partner could be analysed in only one group (A), it seems reasonable to associate this behaviour with social rubbing and lordosis due to its high loading on the factor containing social rubbing and lordosis in this particular group.

Therefore, it appears that overall four clusters exist: (I) social rubbing, lordosis and rolling in front of partner, (II) allogrooming, social sniffing, sniffing rear, nosing and treading, (III) offensive behaviour and staring and (IV) defensive behaviour and staring.

Social rubbing, rolling in front of partner and lordosis are behavioural patterns which are normally shown by females when they are in oestrus to males (see Leyhausen 1979; Michael 1961). They are part of the female sexual repertoire. This cluster is therefore labelled 'sexual behaviour'. The females in the present study showed regular oestrus cycles. When they were in oestrus they directed these behavioural patterns to other females, although social rubbing was also shown when females were not in 
oestrus (see van den Bos \& de Cock Buning 1994a).

The observation that staring is found in both the defensive and offensive factor is not surprising in view of the fact that animals may stare to one another for some time before one of the animals shows any offensive or defensive behaviour. The actor-receiver matrices for staring are nearly symmetrical, whereas the matrices for offensive and defensive behaviours are not (cf. van den Bos \& de Cock Buning 1994a).

The fact that the sexual behavioural patterns are found in one cluster (as expected), along with the fact that defensive and offensive behaviour appear in separate clusters, show the reliability of the factor analysis method used. Therefore the clustering of the behavioural patterns allogrooming, social sniffing, nosing, sniffing rear and treading is not merely a fortunate result of the method, but strongly suggests a true linkage between these behavioural patterns. This has not been observed and reported before.

Nosing, social sniffing and sniffing rear are behavioural patterns which are shown by cats towards one another when they meet (Baerends-van Roon \& Baerends 1979; Leyhausen 1979). Apart from the mother-kitten relationship allogrooming is observed between genetically related and unrelated cats (van den Bos \& de Cock Buning 1994a,b; van den Bos 1995a,c; Brown 1993; Macdonald et al. 1987; Podberscek et al. 1991; Smith et al. 1994). It may be suggested to be an amicable behaviour, i.e., expressing a friendly relationship between cats (cf. Leyhausen 1979). Treading, a behaviour observed in the mother-kitten relationship (see Baerends-van Roon \& Baerends 1979; Moelk 1979), may similarly express friendly relationships between cats. It is therefore tempting to label this cluster collectively 'inspection-affiliative behaviour'.

Recently, Brown (1993; Bradshaw 1992; Bradshaw \& Brown 1992), studied sequential associations of behavioural patterns in single interactions in individuals of two groups of freeranging and one group of non free-ranging neutered cats. Table 3 shows the outcome of her study along with those of the present regarding allogrooming, social sniffing, sniffing rear and nosing. She found that allogrooming and social sniffing were present in the same cluster in those groups in which both behavioural patterns could be analysed. This indicates that they are likely to be shown by cats in single interactions. This might underlie the observed association between allogrooming and social sniffing in the present study. Furthermore as Table 3 shows nosing and sniffing rear were linked with social sniffing and allogrooming, albeit in different ways in different groups. This is in line with the data of the present study. This suggests that these behavioural patterns are likely to be shown by. cats in single interactions (see also Baerends-van Roon \& Baerends 1979; see below).

The similarity between Brown's (1993) results and the present results with respect to the behavioural patterns in cluster II observed in such different groups and with such different methods (Table 3) stresses that these linkages are representative for the cat's social behaviour. At the same time it supports the notion that the

Table 3. Summary of data of the present study using PCA and BROWN's study using Average Linkage Cluster Analysis (1993) on the association of allogrooming, social sniffing, nosing and sniffing rear. Shown are factors (present study) or clusters (BROWN) to which behavioural patterns belong.

NON FREE-RANGING CATS (CONFINED CATS) intact female cats (present study; $n=3$ )

A : - allogrooming, social sniffing \& sniffing rear

— sniffing rear \& nosing

B : - allogrooming, social sniffing \& nosing

— social sniffing \& sniffing rear

C : - allogrooming, social sniffing \& nosing

-allogrooming

- sniffing rear

neutered female and male cats (BROWN; $n=1)$

B-I : - allogrooming, social sniffing \& nosing — sniffing rear

\section{FREE-RANGING CATS}

neutered female and male cats (BROWN; $n=2)$

B-II : - allogrooming, social sniffing \& sniffing rear - nosing $(*)$

B-III : - social sniffing \& sniffing rear - nosing (*)

* : weakly linked to cluster containing allogrooming, social snifing \& sniffing rear and social sniffing $\&$ sniffing rear respectively.

$\mathrm{n}$ : number of groups 
presently used method is valid for studying associations between behavioural patterns.

The implications of the present findings may be shown by a brief discussion of the relationship between the four clusters and the rank order between cats in groups in confinement (see van den Bos \& de Cock Buning 1994a). Offensive behaviour and defensive behaviour are shown by high-ranking and low-ranking individuals respectively in groups living in confinement, where the ranking system is based on the outcome of naturally occurring conflicts (van den Bos \& de Cock Buning 1994a,b). Social rubbing, lordosis (van den Bos \& de Cock Buning 1994a,b; Bradshaw 1992; Macdonald et al. 1987) and rolling in front of partner (Feldman 1994) are more likely to be shown by low-ranking than by high-ranking cats (cf. van den Bos, unpublished data). Whether they are truly submissive behavioural patterns (de Boer 1977; Feldman 1994; Macdonald et al. 1987) remains to be proven however (cf. van den Bos 1995a,b,d; van den Bos \& de Cock Buning 1994a,b; Leyhausen 1979). In contrast to the foregoing it has been shown that allogrooming is shown more often by high-ranking than by low-ranking cats in groups living in confinement (van den Bos \& de Cock Buning 1994a; van den Bos 1995c). This raises the possiblility that the other behavioural patterns in this cluster are involved in expressing this difference in rank as well. The fact that in group $\mathrm{C}$ sniffing rear is associated with offensive behaviour suggests that this may be the case. Leyhausen (1979) already suggested that nosing, social sniffing, and sniffing rear are initiated by more confident animals, which may be expected to be the highranking animals indeed (cf. van den Bos, unpublished data; see however van den Bos \& de Cock Buning 1994a). Comparing group B-II with group B-I (Table 3) furthermore suggests that nosing is more likely to be used in grooming interactions by cats which meet one another regularly (confined animals), whereas sniffing rear is more likely to be used by cats which meet one another on a less regular basis (freeranging animals; see Macdonald et al. 1987). The data of groups B and C confirm this suggstion, whereas group A appears to be an exception to this. The fact that in the latter group a higher level of aggression and a stronger linear rank order were found with cats moving about less freely than in the other groups (van den Bos \& de Cock Buning 1994a; van den Bos 1995a,b) are in line with this suggestion however. This warrants further study.

Overall then it is tempting to suggest that the behavioural patterns of clusters I and II have different roles in maintaining the rank order between cats (see van den Bos \& de Cock Buning 1994a,b). These data therefore encourage studies into the developmental and evolutionary aspects of these behavioural patterns in freeranging and non free-ranging group-living cats (see also Omark 1980), for instance whether this different role is related to a difference in origin of these patterns (maternal, sexual or predatory behaviour) or whether this different role is related to a similar origin but in which the different patterns are displayed by different individuals however. In this respect it is worth nothing that social rubbing (cluster I) is displayed from kittens to their mothers, whereas allogrooming (cluster II) is displayed from mothers to their kittens (e.g. Macdonald et al. 1987). This suggests a relationship between the role in expressing rank-differences (low-ranking to high-ranking animals and vice versa respectively) and the difference between the display of these patterns of individuals at their origin (younger, smaller and weaker animals to older, larger and stronger animals, and vice versa respectively). It may be hypothesized that as cats mature they learn to extend the display of these patterns to other relationships in which differences in size, strength or age, and thereby also in rank (cf. van den Bos \& de Cock Buning 1994a), occur. Indeed, the flow of social rubbing for instance is primarily from juveniles to adults, from females to males (Macdonald et al. 1987; Passanisi \& Macdonald in Bradshaw 1992) and as discussed from low-ranking to high-ranking females (van den Bos \& de Cock Buning 1994a).

Overall then the results of this study as well as their implications serve as an important intermediate step towards understanding the relationship between social structure (which refers to aspects of group composition and spatial patterns of individuals) and social organization 
(which refers to aspects of social interactions between members of groups, i.e. social relationships and patterns of social interactions that give expression to and make up these relationships) in cats as well as how environmental factors affect social structure and social organization in cats (cf. van Schaik \& van Hooff 1983 for primates). In this respect therefore studying the similarities and dissimilarities in behavioural patterns (i.e. the types of interindividual relationships in a stable social organization) in group-living cats under laboratory conditions, i.e. groups with predetermined social structures, contributes along with comparable studies in free-ranging group-living cats (with similar or different social structures) to our understanding of domestic cat (and thereby felid) sociality in general (cf. van den Bos \& de Cock Buning 1994a).

In conclusion, the present study revealed (dis-) simililarities among a set of affiliative and aggressive behavioural patterns on the basis of their distributions across dyads in groups of cats. Overall four clusters of behavioural patterns were found (with only slight differences between groups): (I) sexual behaviour, (II) inspection-affiliative behaviour, (III) defensive behaviour, and (IV) offensive behaviour.

Acknowledgments - The authors wish to express their gratitude to the following persons: Dr. John Bradshaw (University of Southampton, Southampton, U.K.) and Dr. Matthijs Schilder (University of Utrecht, Utrecht, the Netherlands) for comments on an earlier draft of this manuscript; the undergraduate students Marlijn Hoogendoorn and Diane Struik (University of Leiden, Leiden, the Netherlands) for collecting the data of groups B and C; Solvay Duphar BV (Weesp, the Netherlands) for allowing us to study their groups of cats.

\section{Literature}

Baerends-van Roon, J.M. \& G.P. Baerends 1979 The Morphogenesis of the Behaviour of the Domestic Cat; with a special emphasis on the development of prey-catching, North Holland Publishing Company, Amsterdam.

Boer, de, J.N. 1977 Dominance relations in pairs of domestic cats. Behav. Proc. $2: 227$ 242.

Bos, van den, R. \& Tj. de Cock Buning 1994a Social behaviour of domestic cats (Felis lybica forma catus L.): A study of dominance in a group of female laboratory cats. Ethology 98 : 14-37.

Bos, van den, R. \& Tj. de Cock Buning 1994b Social and non-social behaviour of domestic cats (Felis catus L.): a review of literature and experimental findings. In: Welfare and Science (Brunyan, J. ed.), Royal Society of Medicine Press, London, pp. 53-57.

Bos, van den R. 1995a Enige inzichten in het sociale gedrag van katten. Biotechniek $34: 27$ 31.

Bos, van den R. 1995b Recent insights into cat social behaviour. ANZCCART News 8 : 5-6.

Bos, van den R. 1995c Allogrooming in domestic cats in confinement. In: Proceedings of the 29th International Congress of the International Society for Applied Ethology (Rutter, S.M., Rushen, J., Randle, H.D. \& Eddison, J.C. (eds.)), UFAW, Potters Bar UK pp. 109-110.

Bos, van den R. 1995d Behavioural mechanisms to cope with conflict in domestic cats (Felis silvestris catus). ISAZ The Newsletter 9:1920.

Bradshaw, J.W.S. 1992 The Behaviour of the Domestic Cat. C.A.B. International, Wallingford, U.K.

Bradshaw, J.W.S. \& S.L. Brown 1992 Social Behaviour of the cat. Tijdschrift voor Diergeneeskunde 117 (suppl. 1) : 54S-56S.

Brown S.L. 1993 The Social Behaviour of Neutered Domestic Cats (Felis catus), $\mathrm{PhD}$ thesis University of Southampton. Southampton, U.K.

Colmenares, R. 1983 Structure sociale d'une bande de loups iberiques (Canis lupus signatus) en captivite. Strategies et niches sociales. Biology of Behaviour 8 : 27-47.

Dards, J.K. 1983 The behaviour of dockyard cats: interactions of adult males. Appl. Anim. Ethol. 10:133-153

Feldman, H.L. 1994 Domestic cats and passive submission. Anim. Behav. 47:457-459.

Ferguson, G.A. 1981 Statistical Analysis in Psychology and Education. 5th Ed. McGraw- 
Hill Book Company, London.

Harman, H.H. 1967 Modern Factor Analysis, 3rd Ed. University of Chicago Press, Chicago.

Kaiser, H.F. 1958 The varimax rotation criterion for analytic rotation in factor analysis. Psychometrika 23 : 187-200.

Leyhausen, P. 1979 Cat Behavior; The Predatory and Social Behaviour of Domestic and Wild Cats. Garland STPM Press, New York and London (Original publication in German (1956)).

Liberg, O. 1980 Spacing patterns in a population of rural free roaming domestic cats. Oikos $35: 336-349$.

Liberg, O. \& M. Sandell 1988 Spatial organization and reproductive tactics in the domestic cats and other felids. In: the Domestic Cat: the Biology of its Behaviour. (Turner, D.C. \& Bateson, P., eds.) Cambridge University Press, Cambridge, pp. 83-98.

Macdonald, D.W., P.J. Apps, G.M. Carr \& G. Kerby 1987 Social dynamics, nursing coalitions and infanticide among farm cats. Felis catus. Adv. Ethology 28 : 1-66.

Martin, P. \& P. Bateson 1986 Measuring Behaviour: An Introductory Guide. Cambridge University Press, Cambridge.

Michael, R.P. 1961 Observations upon the sexual behaviour of the domestic cat (Felis catus L.) under laboratory conditions. Behaviour 18:1-24.

Moelk, M. 1979 The development of friendly approach behavior in the cat: A study of kitten-mother relations and the cognitive de- velopment of the kitten from birth to eight weeks. Advances in the Study of Behavior Vol 10 (Rosenblatt, J.S., Hinde, R.A., Beer, C. \& Busnel M-C. eds.) pp. 163-224.

Natoli, E. 1985 Spacing patterns in a colony of urban stray cats (Felis catus L.) in the historic centre of Rome. Appl. Anim. Behav. Sci. 14: 289-304.

Natoli, E. \& E. de Vito 1991 Agonistic behaviour, dominance rank and copulatory success in a large multi-male feral cat, Felis catus L., colony in central Rome. Anim. Behav. $42: 227-241$.

Omark, D.R. 1980 The group: a factor or an epiphenomenon. In: Dominance Relations: an Ethological View of Human Conflict and Social Interaction. (Omark, D.R., Strayer F.F. \& Freeman, D.G., eds.) Garland STPM Press, New York and London, pp. 21-67.

Podberscek, A.L., J.K. Blackshaw \& A.W. Beattie 1991 The behaviour of laboratory cats and their reactions to a familiar and unfamiliar person. Appl. Anim. Behav. Sci. 31 : 119130.

Schaik, van C. \& J.A.R.A.M. van Hooff 1983 On the Ultimate causes of primate social systems. Behaviour $85: 91-117$.

Slob, W. 1986 Strategies in Applying Statistics in Ecological Research, $\mathrm{PhD}$ thesis Free University Amsterdam, Free University Press, Amsterdam.

Smith, D.F.E., K.J. Durman, D.B. Roy \& J.W.S. Bradshaw 1994 Behavioural aspects of the welfare of rescued cats. J. Feline Advisory Bureau $31: 25-28$.

(Received 15 May 1996 ; Accepted 1 August 1996) 